\title{
Manufacturing entities flare systems fire hazard analysis
}

\author{
Kostiantyn AFANASENKO *1, Volodymyr LYPOVYI ${ }^{1}$, and Serhii ZIMIN ${ }^{1}$ \\ ${ }^{1}$ National University of Civil Defense of Ukraine, Kharkiv, Ukraine
}

\begin{abstract}
Industrial enterprises of chemical, petrochemical, energy complexes, in the technological process of which combustible gases, flammable and combustible liquids rotate, have flare systems, which are designed for smokeless combustion of combustible and toxic gases or vapors as a result of their periodic, emergency or permanent venting. The main task of flare systems at enterprises is to prevent gas from atmosphere entering by flaring. Flare systems of a manufacturing entities are a complex of structures of high fire danger. The task of the work is to analyze the parameters of the explosion that may occur during the formation of an emergency situation on flare systems.
\end{abstract}

Keywords: flare system, hazard analysis

\section{Introduction}

Flare systems are a complex engineering complex and differ in their elements $[6,8,9]$. Flare systems classification is carried out according to various indicators:

1. Depending on the characteristics of combustible gases and technological features of production distinguish flare systems: general; separate; special.

2. Mode of operation: batch action; permanent.

3. Operating pressure: low pressure; high pressure; local emergency.

4. By molecular weight, temperature, pressure and moisture content in the faulting:

- dry flare system;

- wet flare system.

5. At the place of discharge of gases:

- with discharge of gases into a flare stack; with discharge of high pressure flare gases for processing or for combustion in boiler plants; combined systems.

The flare installation must include a flare tube (barrel) with a burner, flue gas pipes, an ignition system and a labyrinth gland.

6. 6) By location (due to the design of the stack):

- separately located, which are located at a distance of tens or hundreds of meters from buildings and technological devices (high-altitude);

- located on technological installations or near them (ground).

High-altitude flares can be divided into: medium (height 4-25 m); high (height $>25 \mathrm{~m}$ ). Torch barrels can be horizontal and vertical (Figure 1).

Open flare systems can have the following types of barrels (Figure 2) [4]: mast; self-supporting; with paired trunks; on stretch marks. In addition, the flare barrel can be shielded (closed self-supporting) [3].

\footnotetext{
*Corresponding author: E-mail address: armfree0@gmail.com (Kostiantyn AFANASENKO)
} 

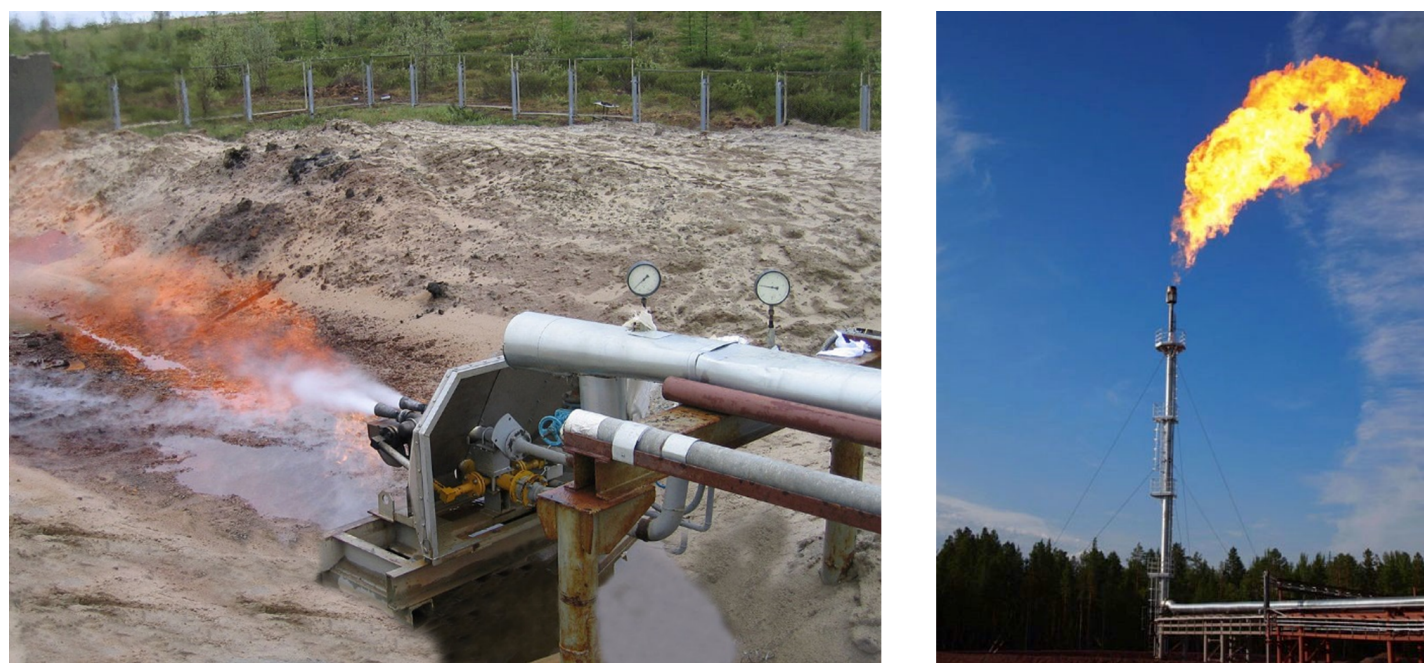

Figure 1. Horizontal and vertical arrangement flare stacks

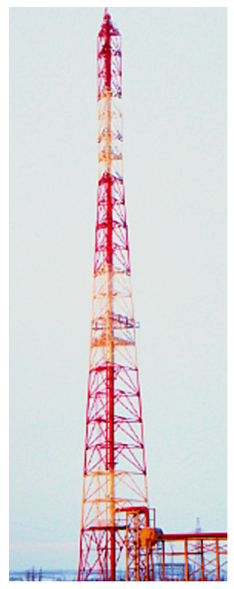

a)

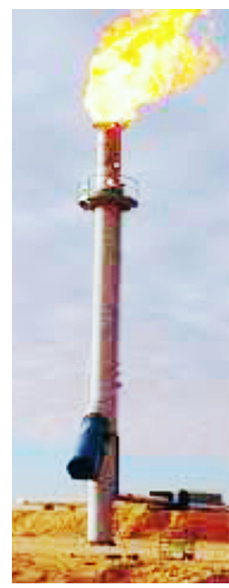

b)

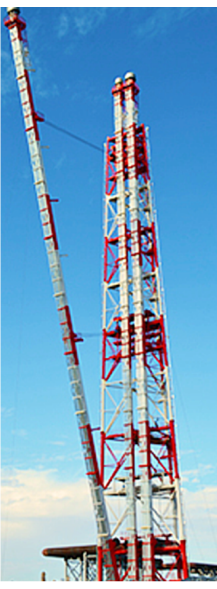

c)

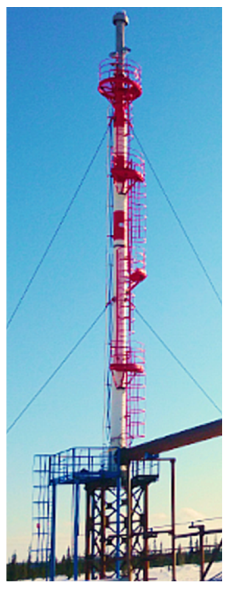

d)

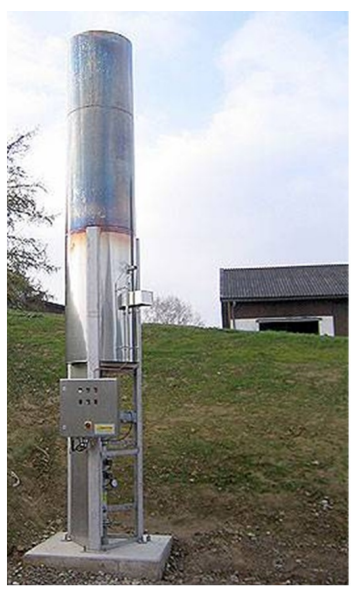

e)

Figure 2. Types of flare stack

a) mast, b) self-supporting, c) with paired stacks, d) on bracing wire, e) closed self-supporting

The paper examine emergencies that may occur when using flare barrels. The most common accidents on flares is $[1,2,7]$ : internal explosion; removal of fluid; system plugging; violation of the operating mode; flame out.

Thus, according to the statistics of emergencies and accidents on flares, the distribution of their causes is as follows (Table 1).

Table 1. Flare stack accidents and incidents

\begin{tabular}{|l|l|l|}
\hline No. & Incidents categories & $\mathbf{\%}$ \\
\hline 1 & Flame out - Operation & 18.6 \\
\hline 2 & Flame out - Unknown & 15.9 \\
\hline 3 & Flame out - Weather & 15.0 \\
\hline 4 & Flame out - Instrumentation & 6.2 \\
\hline 5 & Flame out - Mechanical & 5.3 \\
\hline 6 & Flame out - Steam & 5.3 \\
\hline
\end{tabular}


Table 1. Flare stack accidents and incidents

\begin{tabular}{|l|l|l|}
\hline No. & Incidents categories & $\mathbf{\%}$ \\
\hline 7 & Flame out - Fuel & 4.4 \\
\hline 8 & Flame out - Pilot plugged & 0.9 \\
\hline 9 & Surrounding area fire & 4.5 \\
\hline 10 & Flare pluggage & 3.6 \\
\hline 11 & Material Issues & 3.6 \\
\hline 12 & Flare damage & 2.7 \\
\hline 13 & Flashback - Operations & 2.7 \\
\hline 14 & Flame in muffler & 2.7 \\
\hline 15 & Instrument failure - Operations & 1.8 \\
\hline 16 & Internal burning - coke & 1.8 \\
\hline 17 & Noise & 1.8 \\
\hline 18 & Flare tip crack - Mechanical & 0.9 \\
\hline 19 & Liquid out of flare & 0.9 \\
\hline 20 & Smoke & 0.9 \\
\hline
\end{tabular}

\section{Analysis}

The analysis of tabular data allows to distribute the reasons on their quantitative indicators. Thus, Figure 3 shows that the main percentage of accidents occurs due to the flame out from the head of the torch. Such accidents are dangerous because during their occurrence the formation of a vapor or gas mixture with oxygen is possible, which in the event of an ignition source can form an explosive wave.

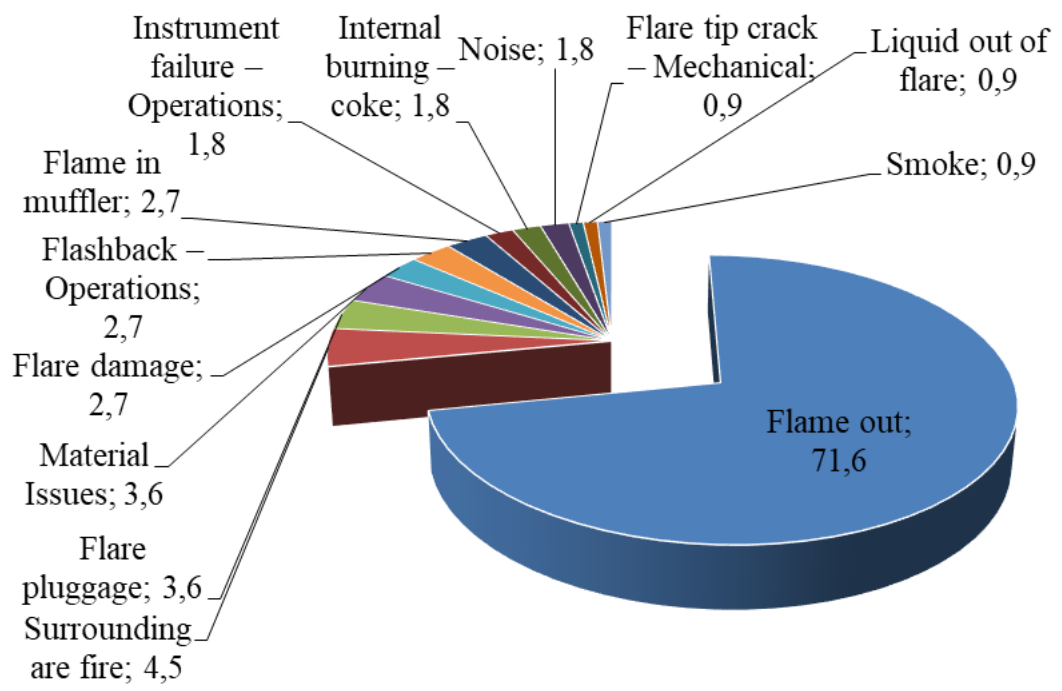

Figure 3. Flare Stack Accidents and Incidents

Thus, the assessment of explosion hazard in the event of such an accident on the flare barrels is an urgent question. For task performing it was made the calculated scheme of the accident, which is shown in Figure 4 . The main structural elements of the flare barrel are indicated: the head of the flare barrel, the flare barrel itself, the mantle of 
the flare barrel. The radius of the zones around the flare barrel, in which the excess pressure explosion can be formed, are given.
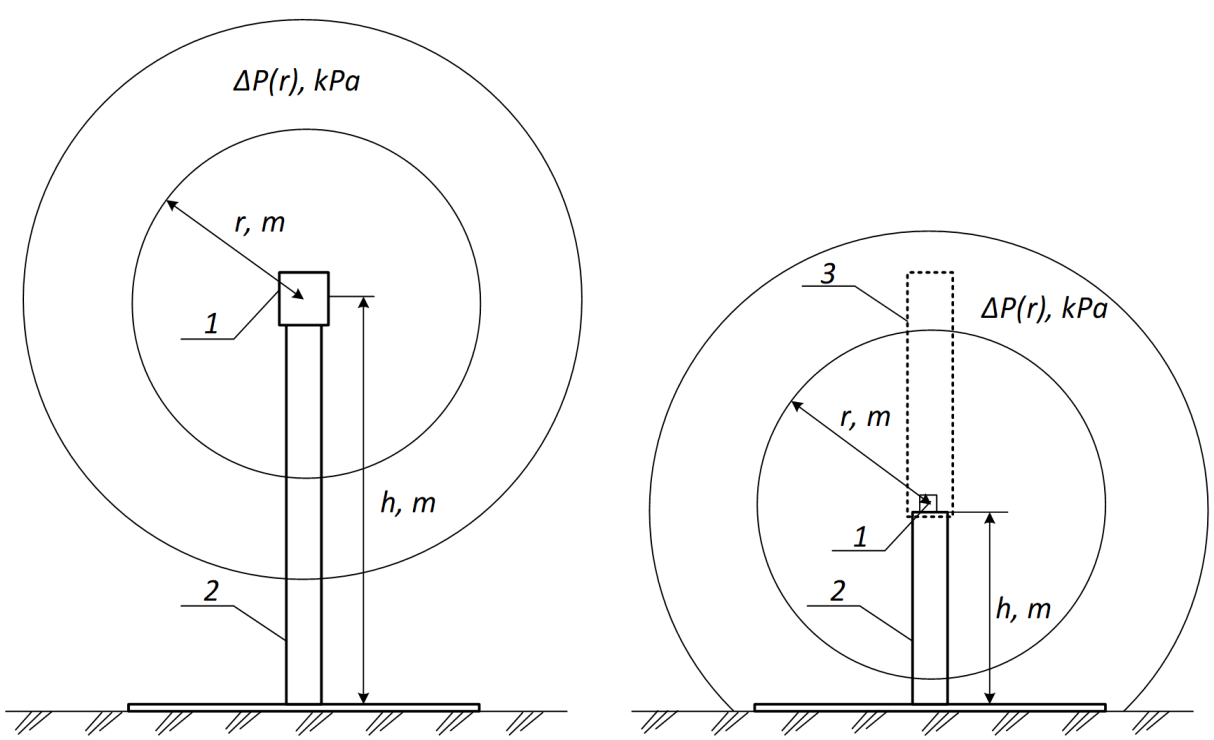

Figure 4. Scheme of flare stacks and calculated parameters of the explosion:

1 - flare head; 2 - flare stack; 3 - mantle; $\mathrm{h}$ - the height of the flare stacks, $\mathrm{m} ; \mathrm{r}$ - the radii of the excess pressure of the explosion, $\mathrm{m} ; \Delta \mathrm{P}$ - excess explosion pressure, $\mathrm{kPa}$

The value of the calculated excess pressure $\Delta \mathrm{P}$ in kilopascals, which develops in the case of ignition of gas and steam mixtures, is determined by the formula [5]:

$$
\Delta P=P_{0} \cdot\left(0.8 \cdot m_{a d}^{0.33} / r+3 \cdot m_{a d}^{0.66} / r^{2}+5 \cdot m_{a d} / r^{3}\right)
$$

where $P_{0}$ - the atmospheric pressure, $(101.3 \mathrm{kPa}) ; \mathrm{r}$ - the distance from the outdoor installation geometric center to the boundary of the calculation zone, $\mathrm{m}$.

The adduced mass of flammable gases and/or vapors of inflammable and combustible liquids in kilograms, is calculated by the formula:

$$
m_{a d}=\left(Q_{c o m b} / Q_{0}\right) \cdot m \cdot Z
$$

where $Q_{c o m b}$ - specific heat of combustion flammable gases and/or vapors of inflammable and combustible liquids, $\mathrm{J} / \mathrm{kg} ; \mathrm{Z}$ - the coefficient of participation of flammable gases and/or vapors of inflammable and combustible liquids in combustion, (0.1); $Q_{0}$ - a constant equal to $4.52 \cdot 10^{6} \mathrm{~J} / \mathrm{kg} ; \mathrm{m}$ - mass of flammable gases and/or vapors of inflammable and combustible liquids, which got into the surrounding space as a result of the calculated accident, $\mathrm{kg}$.

To assess the effects of explosions on critical infrastructure and human resources, the critical values of the explosion overpressure at which various events occur were considered. The effects of the blast wave magnitude on people, buildings and structures are shown in table 2 .

Calculations were performed for three cases of the technological system reaction to the emergency situation. Namely, the overlap of the gas supply valves on the flare device with different times: $\tau_{1}=10, \tau_{1}=120$ and $\tau_{1}=300 \mathrm{~s}$.

Analysis of the calculated data shown in Fig. 5 shows that in the event of an emergency situation involving the flame out from the flare device, the formation of a combustible mixture with the risk of explosion, which results in excess pressure, which will lead to $50 \%$ destruction of building structures in a radius of 7 to $12 \mathrm{~m}$, to the average damage to buildings - from 9 to $17 \mathrm{~m}$, and to the negative impact on people within a radius of $50 \mathrm{~m}$.

In Fig. 6 for the value of the calculated excess explosion pressure of $28 \mathrm{kPa}$, which corresponds to the average damage to buildings, the dependences of the horizontal size of the zone at different heights of the flare barrel. Analysis of the data shown in Fig. 6 shows that redoubling of the flare stack height reduces the negative impact area by up to $400 \%$. 
Table 2. Excess pressure exposure consequences

\begin{tabular}{|c|c|}
\hline Damage rate & Excess pressure, kPa \\
\hline Complete destruction of buildings & 100 \\
\hline $50 \%$ destruction of buildings & 28 \\
\hline Average damage to buildings & 12 \\
\hline Moderate damage to buildings (damage to interior partitions, frames, doors, etc.) & 5 \\
\hline The lower threshold of human injury by a pressure wave & 3 \\
\hline Minor damage (part of the glazing destroyed) & \\
\hline
\end{tabular}
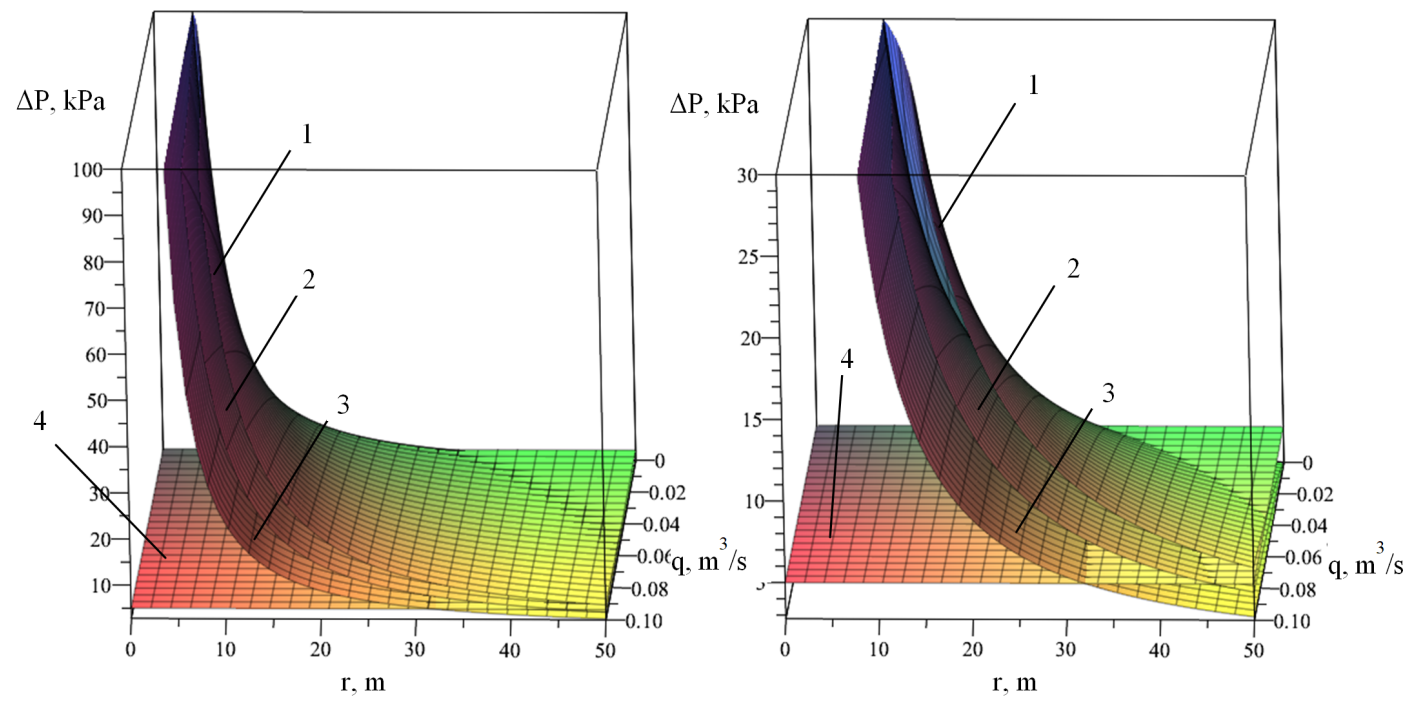

Figure 5. The values of the calculated excess pressure of the explosion depending on the distance from the center of the explosion (r) and gas flow (q): $1-\Delta P\left(\tau_{3}=300 \mathrm{~s}\right), 2-\Delta P\left(\tau_{2}=120 \mathrm{~s}\right), 3-\Delta P\left(\tau_{1}=10 \mathrm{~s}\right), 4-\Delta P=5 \mathrm{kPa}$

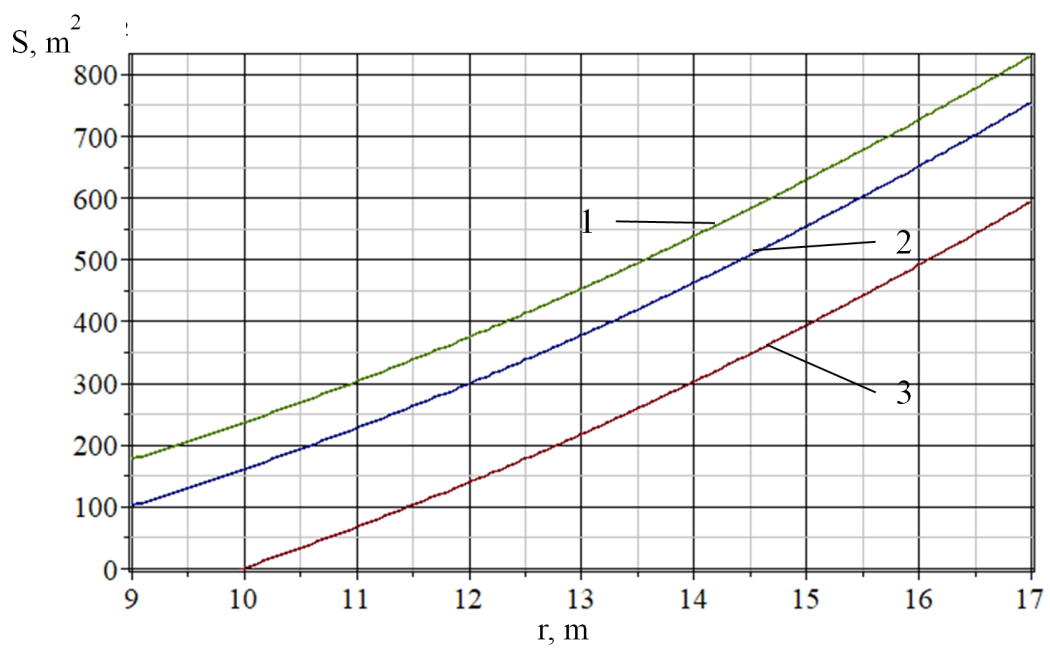

Figure 6. Dependence of the area under the influence of the calculated excess pressure of the explosion on the radius at different heights of the flare stack: $1-\mathrm{h}=5 \mathrm{~m} ; 2-\mathrm{h}=7 \mathrm{~m} ; 3-\mathrm{h}=10 \mathrm{~m}$

\section{Conclusions}

Analysis of a flare systems and flare stacks embodiment allows us to conclude that their fire hazard is represented by the possibility of the formation of an explosive atmosphere in the event of emergencies caused by the «flame out» 
from the flare head. As a result of the calculation it is established that depending on the design features of flare systems the radius of the calculated excess explosion pressure from the ignition of gas mixtures can vary up to $100 \%$. In addition redoubling of the flare stack height reduces the negative impact area by up to $400 \%$.

\section{References}

1. Baryłka, A. \& Obolewicz, J. Empirical veryfication of worksafety evoution. Modern Engineering, 125-130. ISSN: 2450-5501 (3 2020).

2. Baryłka, A. \& Obolewicz, J. Safety and health protection in managing construction projects, Inżynieria Bezpieczeństwa Obiektów Antropogenicznych. ISSN: 2450-1859 (1 2020).

3. Chernyavskij, A. A. \& Maslikov, V. I. Safety analysis in the operation of biogas plants http://elibrary.ru/ projects/articulus/ArticulusFiles/3791/work/200182/3-233-238.pdf.

4. Coker, A. K. Ludwig's Applied Process Design for Chemical And Petrochemical Plants 4th ed. 1 vols. ISBN: 9780-7506-7766-0 (Gulf Professional Publishing, 2007).

5. Determination of categories of premises, buildings and outdoor installations by explosion and fire hazard, $31 \mathrm{p}$. Kyiv, 2016.

6. Klimentova, G. Y., Kachalova, T. N. \& Civunina, I. V. Factory-wide management of chemical enterprises: a tutorial 120 (Kazań, 2010).

7. Kolmetz, K., Lin, A. L., Sutianingsih, Y. \& Ristiyanti, R. Kolmetz Handbook Of Process Equipment Design FLARE SYSTEMS SAFETY, SELECTION, SIZING AND TROUBLESHOOTING (ENGINEERING DESIGN GUIDELINES) https : / /www . klmtechgroup . com/PDF/EDG - SYS /ENGINEERING - DESIGN - GUIDELINES - flare systems-Rev3.4web.pdf.

8. Nazarov, A. A. \& Ponikarov, S. I. Flare systems 118 (KGTU, Kazań, 2010).

9. Strizhevskij, I. I. \& Elnatanov, A. I. Flare systems 184 (Moscow, 1979). 